\title{
A classe por si:
}

\section{Teoria econômica e política em Proudhon e no proudhonismo}

\author{
The class by themselves: \\ Economic theory and policy Proudhon and Proudhonism
}

\author{
Andrey Cordeiro Ferreira \\ Doutor em Antropologia pela Universidade Federal do Rio de Janeiro \\ Professor Adjunto da Universidade Federal Rural do Rio de Janeiro \\ andrey2099@hotmail.com
}

\begin{abstract}
Resumo: O objetivo do presente artigo é apresentar uma reflexão sobre a importância de Proudhon e do proudhonismo para a formação histórica do anarquismo e do sindicalismo. Iremos mostrar que essa contribuição se deu especialmente pela formação de uma teoria da libertação da classe por si, que compreende o associacionismo, o federalismo e o socialismo como mutualismo.
\end{abstract}

Palavras-chave: Anarquismo; Sindicalismo; Proudhonismo; Movimento Operário; Ação Direta

\begin{abstract}
The purpose of this paper is to reflect on the importance of Proudhon and proudhonism for the building of anarchism and syndicalism great tradition. We will show that this contribution was given especially by the constitution of a theory of liberation of working classes by themselves, comprising syndicalism, federalism and socialism as mutualism.
\end{abstract}

Keywords: Anarchism; Syndicalism; Proudhonism; Worker Movement; Direct Action

Originais recebidos em: 24/06/2015

Aceito para publicação em: 25/08/2015

\section{(c) $($ () $\ominus$}

EY NC ND Este trabalho está licenciado sob uma Licença Creative Commons Atribuição-Uso NãoComercial-Vedada a criação de obras derivadas 3.0 Unported License. 


\section{Introdução}

Em 19 de janeiro de 1865, morreu Pierre-Joseph-Proudhon que, ao lado de Mikhail Bakunin, é o principal teórico do sindicalismo e do anarquismo internacional no século XIX. A obra de Proudhon no Brasil e em diversas partes do mundo é comumente analisada a partir da (e reduzida à) crítica de Marx ao Sistema das Contradições Econômicas realizada em Miséria da Filosofia, sendo muito pouco estudada, seja no conteúdo, seja na influência que exerceu sobre o movimento operário e socialista. Esse juízo historiográfico sobre a irrelevância do pensamento de Proudhon será reafirmado na nota cronológica escrita por Marx (MARX, 1982). A historiografia marxista do movimento operário e socialista geralmente reafirma de forma acrítica os juízos de Marx sobre Proudhon. Dessa forma reproduz aquilo que denominamos de anarquismo como anticonceito, ou seja, ao anarquismo não é reconhecida nenhuma formulação política ou científica, apenas propriedades inversas e negativas ao marxismo (Ferreira, 2014). Essa abordagem, que é reproduzida inclusive em historiadores de diversas matrizes ideológicas, tem dois problemas metodológicos: em primeiro lugar, a apresentação do conteúdo do pensamento de Proudhon é precária, não existe um procedimento de apresentação compreensiva antes da crítica, apenas parte-se da reafirmação do juízo que Marx fez das mesmas; em segundo lugar, se explica esse conteúdo atribuído à Proudhon em termos economicistas, sendo o principal argumento de que Proudhon seria "pequeno-burguês" em razão da sua origem de classe de artesão. A abordagem historiográfica, então, não consegue nem compreender o pensamento proudhoniano, nem explicar sua complexa inserção na estrutura do capitalismo do século XIX.

Uma análise substantiva do pensamento de Proudhon foi realizada por Georges Gurvitch, sociólogo coletivista (Gurvitch e Proudhon, 1965) e mesmo por Durkheim, para quem Proudhon aparece como um dos precursores da sociologia (Durkheim, 1982). Nessas obras, Proudhon é indicado como um dos principais formuladores de conceitos, teses e métodos da economia política e sociologia. Entretanto, pouco é analisado de sua relação com o movimento operário e a ação política, ou quando sim, não se menciona sua relação com o anarquismo. Mas essa análise já e suficiente para mostrar a fragilidade da historiografia dedutiva, que deduz a análise de conteúdo do pensamento de Proudhon da crítica de Marx, desconsiderando as evidências documentais e se fragilizando assim como interpretação. 
É na historiografia anarcocomunista em que Proudhon é colocado como uma das figuras canônicas do anarquismo e do sindicalismo. Mas nessa abordagem, o conceito de anarquismo tem duas propriedades, ele é anacrônico e naturalizado, considerado como um traço da natureza humana (Joll e Duarte, 1977; Tragtenberg, 1987; Woodcock, 2002; Ferreira, 2014). Uma crítica tem sido realizada no Brasil e outras partes do mundo a este conceito "elástico" e anticientífico de anarquismo, buscando uma redefinição mais precisa que permita uma reconstrução da história do anarquismo e do sindicalismo (Schmidt e Van Der Walt, 2009; Corrêa, 2013 (Publicada em julho de 2015); Ferreira, 2014). Lucien van der Walt no seu livro "Chama Negra" formula uma crítica análoga à nossa formulação do conceito elástico de anarquismo, e propõe definir o anarquismo como fenômeno da "primeira internacional".

Mas isso gera uma dificuldade sobre o enquadramento de Proudhon e sua obra. Se o anarquismo tem sua constituição efetiva por meio da materialização do "dualismo organizacional" (da relação entre a organização anarquista e a organização de massas na AIT), Proudhon estaria excluído dessa tradição anarquista, logo ele que foi o primeiro a reivindicar o anarquismo como categoria política positiva? Em primeiro lugar entendemos que essa questão pode ser abordada de duas formas. Se considerada como um movimento taxonômico, de atribuir etiquetas de inclusão e exclusão, ela é uma falsa questão e, mesmo, sem importância. Mas do ponto de vista teórico e histórico, ou seja, da análise dos processos reais, é uma questão relevante. A resposta está no nosso entendimento da teoria: uma história "heróica", centrada no indivíduo, leva às falsas questões apontadas acima. Mas quando consideramos as forças coletivas e a relação de Proudhon com o "proudhonismo" (conjunto de militantes e ativistas que reivindicavam as ideias proudhonianas), esse problema fica resolvido. Nesse sentido poderíamos apresentar a seguinte tese: o proudhonismo (que engloba a atividade do desenvolvimento do sistema teórico de Proudhon e suas apropriações contraditórias) foi a força que constituiu o anarquismo dentro da AIT e esta força passou por transformações de nominação que confundem alguns historiadores (as categorias de mutualismo, coletivismo, bakuninismo). Dessa forma, se considerarmos Proudhon como um indivíduo isolado a resposta à questão seria não; se rompermos com o individualismo metodológico e considerar o proudhonismo como fenômeno coletivo a resposta é sim. Essa é uma ambiguidade constitutiva da história da AIT e do anarquismo. A teoria e a prática de resistência operária proudhonista é que geraram a tradição anarquista. O proudhonismo é um fenômeno da década de 1850-60 e é essa 
força coletiva que irá constituir a "grande tradição anarquista" (Van Der Walt, 2009). Iremos analisar agora alguns aspectos do pensamento de Proudhon e do proudhonismo.

\section{A dialética e a insurreição do pensamento: economia política e crítica da propriedade}

O debate sobre o pensamento de Proudhon precisa dialogar com a historiografia marxista. No nosso entendimento, o anticonceito marxista de anarquismo produz um duplo efeito: ele nega qualquer teoria ao anarquismo e, por isso, impede a análise da teoria anarquista e consequentemente faz uma história deficiente das relações entre a teoria anarquista e a teoria comunista. A divergência entre Marx e Proudhon deriva das suas diferentes concepções em torno de três temas: relação da ciência com a política; economia política e papel econômico do Estado; se o processo revolucionário seria mediado pelo Estado e pelo Partido (libertação para si) ou realizado diretamente pela

classe trabalhadora (libertação por si). É nesse sentido que iremos apresentar aqui o que chamamos de três proposições fundamentais da teoria de Proudhon: o projeto de ciência como saber insurgente; a economia política como teoria das instituições econômicas e do governo; a teoria da libertação da classe por si.

A cisão entre Proudhon e Marx na realidade não é motivada, como Marx apresenta, pelo caráter "idealista" da proposição proudhoniana, mas sim pela diferença em relação a um conjunto de temas: 1) o determinismo econômico; 2) o papel do Estado; 3) o conceito de comunidade e comunismo. Estes temas resumem todas as grandes diferenças político-intelectuais levantadas no campo do movimento socialista do século XIX. É no Livro "Miséria da Filosofia" (escrito em resposta a "Filosofia da Miséria”, de Proudhon) que Karl Marx, entre muitas das objeções que levanta, explicita este ponto central de divergência:

Assim, pois, a arbitrariedade dos soberanos é, para o senhor Proudhon, a razão suprema na economia política. Verdadeiramente faz falta a ignorância absoluta da história, para não saber que, em todos os tempos, os soberanos tiveram que submeter-se as condições econômicas, sem poder ditar-lhes nunca sua lei. Tanto a legislação política como a civil não fazem mais que expressar e protocolizar as exigências das relações econômicas. (MARX; ENGELS, 1985).

O trecho acima mostra a marca de toda a diferenciação que seria levantada entre anarquistas e comunistas, que diz respeito à concepção ontológica da história e o lugar do econômico. Marx atribui a Proudhon a compreensão de que o Estado cumpre um papel determinante na história e na economia política, ao passo que ele considera os 
soberanos (o Estado) como apenas o realizador dos movimentos da economia. A compreensão do lugar do político em relação ao econômico e como cada um determinaria o conjunto da existência social, abriria o campo das múltiplas oposições que marcariam as diferenças entre eles. Esta diferença seria formulada fundamentalmente na definição conceitual de Marx de infraestrutura econômica e superestrutura político-ideológica, em que o primeiro determinaria em última instância o segundo. Não é aqui o espaço para estudar detidamente a história das cisões entre Marx-Engels e Proudhon. Por isso, basta dizer que esta reflexão sobre o lugar do político expressa a distância entre dois posicionamentos teóricos que partem de uma base filosófica relativamente comum, a dialética.

Podemos destacar aqui algumas obras de Proudhon que são estratégicas para enfrentar esses problemas: "O Que é a Propriedade? Ou princípio do direito e do governo" (1840); "Da criação da ordem na Humanidade" (1843), "Sistemas das Contradições Econômicas ou Filosofia da Miséria" (1846), "Do Princípio Federativo da necessidade de reconstituir o Partido da Revolução" (1863) e sua obra póstuma "Da Capacidade Política das Classes Operárias" (1865). São essas obras que iremos analisar aqui, já que as mesmas apresentam o conteúdo principal da teoria do autor.

Primeiramente, é importante marcar que o livro de Proudhon "O que é a Propriedade?” (1840) apresenta a problematização do discurso de constituição da sociedade burguesa. Nele, a crítica dos fundamentos de legitimação da propriedade abrirá espaço para a recusa dos principais pressupostos de teorias sociais subsequentes, como o evolucionismo e o racismo científico ${ }^{1}$. As teses de origem da propriedade (direito natural, ocupação, trabalho) são todas questionadas, para afirmar-se que a propriedade é, em última instância, produto da força e por ela sustentada. A mesma crítica seria direcionada ao Governo. Desta maneira, os dois principais indicadores da "civilização", seriam submetidos a uma crítica severa. A partir desta consideração, e depois de analisar a constituição francesa de 1793 e o Código Napoleônico, concluiu que: "Distinguem-se na propriedade: $1^{\circ}$ ) a propriedade pura e simples, o direito senhorial sobre a coisa, ou, como se diz, a propriedade nua; $2^{\circ}$ ) a posse.(...) Esta dupla

\footnotetext{
${ }^{1}$ Notemos que a discussão sobre o racismo, as nacionalidades e o patriotismo foi feita de forma relativamente transversal à questão das classes e do capitalismo. A recusa do racismo é operada por Proudhon ao discutir a escravidão nos Estados Unidos da América, onde afirma não haver desigualdade entre as raças.
} 
definição enquanto domínio e posse é da mais alta relevância; e é preciso apreende-la bem para compreender o que temos a dizer" (PROUDHON, op.cit: 42).

Vemos na definição do fato econômico da propriedade residir a ideia de domínio (do latim dominus, direito ou autoridade do senhorio sobre alguma coisa, termo intercambiável com dominatione, dominação), o que coloca no centro da noção de propriedade o poder, que conjugado com a noção de direito, consagraria a legitimidade da propriedade por um sistema legal. No âmago das relações econômicas, na definição mesma da noção de propriedade, reside o fato da dominação e consequentemente, o elemento político. Mas a propriedade é tomada também como instituição base e princípio do Governo, segundo os termos de Proudhon, ou do sistema político, para empregar uma linguagem conceitual mais definida. E esta injunção se conjuga com uma definição econômica do governo: “O Governo é a economia pública, a administração suprema dos trabalhos e dos bens de toda uma nação" (Proudhon, op.cit: 178). A propriedade e a economia se definem pela política, e a política se define pela economia. Os termos, separados e opostos pela teoria e pela prática social, na análise de Proudhon só alcançam sua plena definição um através do outro ${ }^{2}$.

Esta visão da dialética da política com a economia, como crítica do determinismo econômico, é assim a formulação mais precisa da diferença entre Proudhon e Marx. Ao contrário de considerar o Estado ou o Governo como um instrumento passivo das forças econômicas, Proudhon considera que Governo é economia, um agente construtor e parte das contradições econômicas. O livro "O Que é a Propriedade?" não é um livro de economia: é um livro que poderíamos considerar de sociologia jurídica. Proudhon tenta mostrar como o direito de propriedade privada, consagrada pelas modernas revoluções, entra em contradição com um fato sociológico: a produção e a força coletiva do trabalho (reconhecido como princípio gerador da propriedade) não levam ao direito de propriedade, mas à sua negação.

Mas é no livro "Sistema das Contradições Econômicas ou Filosofia da Miséria, vol. I e II" que o autor estabelece sua crítica da economia política e essa teoria dialética de forma acabada. O livro não se propõe a ser uma análise puramente econômica do capitalismo, mas sim uma abordagem filosófica (ou seja, a partir de um ponto de vista

\footnotetext{
${ }^{2}$ Este procedimento dialético do autor é mais identificável quando ao final desta obra, discute os modelos de organização social, definindo três regimes: $1^{\circ}$ propriedade, ou a tese; $2^{\circ}$ comunidade, ou a antítese. Da superação das contradições deriva o terceiro, o regime de liberdade, como síntese social da economia com a política.
} 
ético-político) do que produz a miséria e a desigualdade social. ${ }^{3}$ Nesse sentido, é preciso ter uma chave de leitura bem determinada: o livro está assentado na proposição da teoria do valor trabalho (e não na teoria da mais valia como faria Marx anos depois), e na expectativa de demonstrar que o valor tal como se supunha ser formado pela lei da oferta e procura (economia política burguesa) era um equívoco, mas que também a proposição da regulação estatal para controlar o valor (feita por socialistas e comunistas) não era uma solução econômica factível. Ou seja, não se deve buscar nesse livro uma teoria do funcionamento da economia capitalista, mas sim uma crítica de como o valor na economia capitalista não expressava o valor trabalho de forma efetiva, gerando assim desigualdade social e miséria. Certamente, ao apresentar o caráter sistêmico (e cada uma das categorias dialéticas que compõem o capitalismo), ele avança na teorização econômica, mas não pode ser reduzido a economia tal como entendida hoje.

O sistema das contradições econômicas é assim fundado sobre a contradição do valor: composto por valor de uso e valor de troca, a economia moderna não reconhece na realidade a dimensão sintética e logo o valor não chega a ser o valor constituído (ou seja, valor trabalho com o pagamento e instituição da relação proporcional entre valor de uso e valor de troca). A inexistência dessa proporcionalidade do valor era assim a primeira e fundante contradição econômica. O valor na sociedade capitalista, apesar de ser produzido pelo trabalho, não reflete isso de forma plena: os economistas burgueses acreditavam que o valor de troca expressaria a melhor ordem social, ao permitir o desenvolvimento do comércio; os socialistas acreditavam que regulando a produção de "valores de uso" através do Estado para satisfazer as necessidades básicas seria a solução, evitando assim a superprodução. Mas nos dois casos, não se buscava constituir o valor a partir do valor trabalho. Proudhon aponta que na realidade somente uma distribuição proporcional de valores de uso e troca na economia social poderia produzir a igualdade, lembrando que esta assertiva estava associada ao pressuposto do fim da propriedade privada e reconhecimento da força coletiva como geradora de um direito coletivo. Logo, se no plano do direito, o trabalho e força coletiva geram um direito coletivo que não é reconhecido pelo direito de propriedade, no plano econômico implicava que o valor nunca refletia a centralidade do trabalho na sua constituição.

\footnotetext{
${ }^{3}$ É importante observar que "O Que é a Propriedade?" e "Filosofia da Miséria" buscam responder questões levantadas em concursos públicos da Academia de Ciências Morais e Políticas de Paris.
} 
Essa relação entre propriedade privada e valor é ainda complementada por pares dialéticos que ordenam a economia moderna: divisão do trabalho e mecanização; concorrência e monopólio; o papel da polícia ou imposto (que é a intervenção governamental e estatal na economia e nos outros fatores). Desta maneira, o que as contradições econômicas apresentam é que para cada fator de expansão da produtividade dos valores dentro da economia moderna existia um fator de opressão do trabalhador e geração de desigualdade. A divisão do trabalho levava a uma maior eficiência do trabalhador, mas também à sua dependência e alienação; a maquinaria e desenvolvimento tecnológico, possibilitando uma jornada de trabalho menor e assim a libertação do trabalhador, produzia a tendência ao desemprego; a concorrência, expressão da liberdade de comércio que deveria levar os preços para baixo, tendia, na realidade, a produzir o monopólio; o Estado, por sua vez, representa a manutenção do trabalho improdutivo através do imposto que deveria ser uma redistribuição social, na realidade reverte este ganho para sua manutenção (criando assim o que hoje é o problema crônico do déficit fiscal) de forma que não conseguiria resolver as contradições econômicas.

Analisando a série das contradições, no capítulo dedicado “às máquinas" ele mostra mais claramente a contradição inerente a esta dependência mútua entre trabalho e capital. De um lado os capitalistas que exploram o trabalho e tendem pela dinâmica econômica a expulsar os trabalhadores da produção para aumentar sua acumulação; mas somente o trabalho gera o valor, o capital para ser acumulado, fazendo com que o capitalista seja "refém do trabalhador". De outro lado, o trabalhador que é explorado e expropriado pelo capitalista (do ponto de vista da teoria do valor trabalho, a mais valia é a espoliação) é obrigado a vender sua força de trabalho para o capitalista para poder garantir sua reprodução social enquanto sujeito real e vivo. Assim, no poder absoluto do capital existe um limite, a impossibilidade de existir sem o trabalhador; do lado deste último, na sua única forma de existência reside também o elemento que reproduz sua subordinação e dependência e, ao mesmo tempo, seu poder social.

A dialética serial reconstitui o surgimento cumulativo na história das diferentes instituições que compõem o sistema econômico: a dialética valor de uso/de troca é inerente à economia; logo, esta dualidade está presente em toda a história, assim como a dialética autoridade/liberdade; a divisão do trabalho e a mecanização surgem na história como parte do processo de desenvolvimento humano, antes da concorrência e do monopólio, da moeda/crédito e também do Estado como agente distribuidor e da 
balança comercial como fator regulador da economia internacional. As categorias antinômicas (tendência e contratendência representada por cada um desses princípios econômicos, constitui a série das contradições econômicas que constitui o sistema capitalista). Não é possível mudar o sistema mudando ou agindo apenas sobre um dos termos da série.

\begin{abstract}
Assim, no valor, não há nada de útil que não se possa trocar e nem nada de trocável que não seja útil: o valor de uso e o valor de troca são inseparáveis. (...) Os efeitos desta luta são conhecidos: as guerras comerciais e de mercados, a superprodução, a estagnação econômica, as proibições, os massacres da concorrência, o monopólio, a depreciação dos salários, as leis de máximo, a esmagadora desigualdade das fortunas, e a miséria, decorrem todas da antinomia do valor. Ser-me-á dispensado dar aqui a demonstração destes fatos, que, aliás, decorrerá naturalmente dos capítulos seguintes. (PROUDHON, 2003, p. 136).
\end{abstract}

Proudhon funda uma crítica do capitalismo que não se vincula à crença de que o capitalismo cria as condições para o socialismo, mas ao contrário, ele vai buscar em princípios econômicos marginais ao sistema (a reciprocidade, o valor constituído em alguns setores) os fundamentos de uma nova ordem social. A principal descoberta dessa obra é esta: que a lei do desenvolvimento capitalista é o desenvolvimento das suas próprias contradições; a economia capitalista é contraditória, ela não realiza a liberdade (comercial e econômica) e igualdade (política) que a economia política e o liberalismo anunciam. Essa descoberta vincula essas contradições ao papel econômico do Estado, já que este não figura como regulador exterior, mas como parte das contradições econômicas através do Imposto/Balança Comercial.

A ideia de ciência em Proudhon tem então dois sentidos: a ciência tem como objetivo a explicação do social; a ciência tem como objetivo a mudança social. Esse lugar do social no duplo sentido de objeto e de processo de mudança marcará a forma com o anarquismo concebe a relação entre teoria e prática e o diferencia do marxismo. Daí o fato de que a "ciência exige a insurreição do pensamento", ou a ruptura com os sistemas de conhecimento dominantes. A ciência insurgente deve questionar as teses dominantes sobre a política econômica, daí o ataque ao liberalismo e ao comunismo franceses.

\title{
A classe por si: federalismo e capacidade política dos trabalhadores
}

Uma característica fundamental do pensamento e da abordagem sociológica de Proudhon, na qual este se difere de Marx e de todos os economistas burgueses, é que o primeiro pensou e aplicou a concepção dialética e os conceitos gerais da filosofia ao 
estudo do poder e da política, rompendo com o predomínio do econômico característico de Marx e dos liberais do século XIX e XX. Essa transposição das categorias e conceitos gerais da filosofia dialética está formulada no seu livro "Do Princípio Federativo" e é expresso pelo encadeamento de conceitos que começam com a dialética autoridade-liberdade, passando pelo conceito de regimes políticos até o conceito de forma de governo. Mas não somente o autor faz um diagnóstico dos regimes políticos e formas de governo, mas delineia uma forma de governo a partir da sua crítica.

O primeiro componente da teoria do poder e da política é o dualismo político, a dialética entre autoridade e liberdade, que figurando como conceitos gerais-abstratos está na base da formulação dos conceitos particulares-concretos da análise política. Vejamos como o autor coloca o problema:

A ordem política repousa fundamentalmente em dois princípios contrários, a Autoridade e a Liberdade: o primeiro iniciador, o segundo determinante; este tendo por corolário a liberdade de pensamento, aquele a fé que obedece (...) A Autoridade supõe necessariamente uma Liberdade que a reconheça ou a negue; a liberdade por seu lado, no sentido político do termo, supõe igualmente uma autoridade que lide com ela, a reprima ou a tolere. Suprimase uma das duas, a outra não faz mais sentido: a autoridade, sem uma liberdade que discuta, resista ou se submeta, é uma palavra; a liberdade, sem uma autoridade que a equilibre, é um contrassenso. (PROUDHON, 2001, p. 46).

Aqui nós vemos dois movimentos. Em primeiro lugar, a existência da dialética, a unidade dos contrários e o antagonismo. Ao mesmo tempo, existe uma determinada compreensão da dialética já que não existe uma síntese possível entre os dois termos, apenas o antagonismo e o balanceamento de forças da luta entre os dois polos da unidade contraditória.

Essa unidade contraditória inerente à política se alinha a outra ideia extremamente importante que é a da inexistência de sistemas absolutos, ou seja, não é possível que num regime autoritário toda liberdade seja suprimida e nem num sistema libertário toda autoridade. Nesse sentido, o equilíbrio entre os dois princípios é o que é determinante para a formação dos regimes e governos. Daí que essa dialética encontra seu campo de expressão última não em si mesma, mas na forma como a política se realiza. Vejamos:

Esta condição é absoluta; nenhuma combinação política se lhe pode eximir. A despeito do entendimento cujo esforço o leva incessantemente a resolver a diversidade na unidade, os dois princípios continuam presentes e sempre em oposição. O movimento político resulta da sua tendência inelutável e da sua mútua reação. (PROUDHON, 2001, p. 47). 
A dialética é aqui definida como uma luta perpétua entre dois termos; o polo da autoridade e o polo da liberdade apresentam-se assim como irredutíveis e indissolúveis. Esse aspecto é importante, pois como cada princípio irá se expressar em regimes políticos de liberdade ou autoridade podemos concluir que na realidade existe uma luta perpétua entre regimes na história (regimes de liberdade contra regimes de autoridade) e também dentro dos regimes de liberdade para fazer prevalecer o princípio da liberdade contra a autoridade. Podemos daqui extrair não somente um instrumento para a análise da ciência política e sociologia. A dialética interna à política é definida pela luta entre categorias, assim como a dialética interna à economia é definida pela contradição entre valor de uso e valor de troca (Proudhon, 2001: 55-56). É com essa formulação que o autor chega não mais à dialética interna do movimento político, mas à dialética entre regimes políticos, o que ele denomina de regime de autoridade e regime de liberdade.

Aqui então é anunciado um tema fundamental: o que caracteriza os diferentes regimes é a indivisão/centralização (autoridade) e a divisão/descentralização (liberdade) do poder. O conceito de forma de governo é chave para entendermos essa elaboração: "Chama-se formas de governo a maneira como se distribui e se exerce o Poder. Natural e logicamente estas formas estão em relação com o princípio, a formação e a lei de cada regime" (Proudhon, 2001: 60). O problema do poder, nesta perspectiva, está ligado a dois conceitos: distribuição e exercício, orientados sempre pela prioridade da autoridade sobre a liberdade ou da liberdade sobre a autoridade. Onde está então o elemento que, orientado pela dialética autoridade-liberdade, pelos regimes e formas de governo, possibilita a transição da lógica dialética da política à prática ilógica dos governos de fato? Na luta de classes. A distribuição do poder, a dialética autoridade-liberdade e todos os conceitos vão do geral-abstrato ao particular-concreto por uma série de mediações cuja síntese é a luta de classes:

\footnotetext{
A luta de classes, o antagonismo dos seus interesses, a maneira como esses interesses se ligam, determina o regime político, e, consequentemente, a escolha do governo, as suas inumeráveis variedades e suas variações mais inumeráveis ainda. Pouco a pouco todas essas classes se reduzem a duas: uma superior, Aristocracia, Burguesia ou Patriciado; uma inferior, Plebe ou Proletariado; entre as quais joga a Realeza, órgão do Poder, expressão da Autoridade. (PROUDHON, 2001, p. 69-70).
}

Aqui temos então um elemento fundamental da dialética proudhoniana (que será retomada por Bakunin): o antagonismo no plano ontológico-filosófico (a oposição irredutível) se resolve na história pelo conceito de luta de classes. É a luta de classes que determina a forma dos governos e dos regimes políticos. Ou seja, o antagonismo entre 
autoridade-liberdade na lógica não é suficiente para explicar a formação dos governos de fato, mas esse antagonismo autoridade-liberdade passa no plano da história pela luta de classes: os governos de fato surgem das transações de princípios ocasionadas pela luta de classes, pelo caráter contingente das disputas de interesses e das relações de força.

Dessa maneira, das formas de governo possíveis, dentre aquelas experimentadas empiricamente se encontravam especialmente três: o Império, a Monarquia Constitucional e a Democracia ou República Unitária. O esquema abaixo permite que visualizemos exatamente como a dialética filosófica só encontra sua síntese na complexidade concreta, na qual os regimes e formas de governo se realizam numa multiplicidade de possibilidades. Aqui então o autor usa os dois termos para qualificar historicamente a forma de governo monárquico, o Império e Monarquia Constitucional. Para cada forma de governo existe, na perspectiva de Proudhon, certa aliança de classes entre classes baixas, altas e Estado ou autoridade.

\begin{tabular}{|c|c|c|c|c|c|c|c|}
\hline \multirow{4}{*}{$\begin{array}{l}\text { Luta de } \\
\text { Classes }\end{array}$} & \multicolumn{7}{|c|}{ Dualismo Político Autoridade-Liberdade (Abstrato) } \\
\hline & \multicolumn{4}{|c|}{$\underline{\text { Regime de Autoridade (Abstrato) }}$} & \multicolumn{3}{|c|}{$\underline{\text { Regime de Liberdade (Abstrato) }}$} \\
\hline & \multicolumn{2}{|c|}{$\begin{array}{l}\text { Monarquia (Forma de } \\
\text { Governo) }\end{array}$} & \multicolumn{2}{|c|}{$\begin{array}{l}\text { Comunismo (Forma de } \\
\text { Governo) }\end{array}$} & \multicolumn{2}{|c|}{$\begin{array}{l}\text { Democracia } \\
\text { (Forma de Governo) }\end{array}$} & $\begin{array}{l}\text { Anarquia } \\
\text { (Forma de }\end{array}$ \\
\hline & $\begin{array}{l}\text { Império } \\
\text { (governos de } \\
\text { fato) }\end{array}$ & $\begin{array}{l}\text { Monarquia } \\
\text { Constitucio } \\
\text { nal } \\
\text { (governos } \\
\text { de fato) }\end{array}$ & $\begin{array}{l}\text { Comunida } \\
\text { des } \\
\text { Patriarcais } \\
\text { sem chefia }\end{array}$ & $\begin{array}{l}\text { Estado } \\
\text { Intervencion } \\
\text { ista } \\
\text { (governos } \\
\text { de fato) }\end{array}$ & $\begin{array}{l}\text { Democrac } \\
\text { ia Unitária } \\
\text { (governos } \\
\text { de fato) }\end{array}$ & $\begin{array}{l}\text { República } \\
\text { Federativa } \\
\text { (governos } \\
\text { de fato) }\end{array}$ & $\begin{array}{l}\text { República } \\
\text { de } \\
\text { Comunas } \\
\text { Federalizad } \\
\text { as } \\
\text { (governos } \\
\text { de fato) }\end{array}$ \\
\hline
\end{tabular}

Em resumo, a teoria do poder e dos regimes políticos está assentada no nível geral-filosófico no conceito de dualismo político e no nível concreto na luta de classes, na qual a relação dialética entre política e economia dá explicação última para a oscilação histórica entre regimes políticos e formas de governo, as transações concretas e a multiplicidade histórica dos mesmos. É exatamente aqui que a teoria do poder está assentada na teoria econômica e filosófica do autor, referida inicialmente. Na economia, o problema do valor e da desigualdade é considerado sob o aspecto da resolução da contradição do valor, através de uma fórmula que visa constituir o valor trabalho como 
fundamento da economia e do direito. Para Proudhon o poder está assentado então em três conceitos gerais-abstratos: o conceito de dialética autoridade-liberdade, a autoridade representando a concentração do poder e do comando, e a liberdade representando a divisão do poder e a autonomia; o conceito de desenvolvimento como progresso/retrocesso e não como passagem do germe ao ser completo; o conceito de transação, enquanto um movimento do lógico ao histórico e do histórico ao lógico, no sentido que o real não é uma mera aplicação do teórico, mas ao mesmo tempo ele engloba a dialética como oposição da qual a própria luta de classes é o fator de síntese, gerando as transações e contradições da política, o que também implica um antagonismo e transação perpétua entre os regimes políticos e formas de governo.

A partir destes conceitos são formadas as características centrais da matriz anarquista de análise do poder: 1) a política não é vista como um reflexo exterior e determinado da economia, mas é pensada a partir de uma dialética constitutiva que é a dialética entre autoridade e liberdade como princípio ordenador da distribuição e exercício do poder; 2) a análise da política é baseada na reflexão sobre os regimes políticos, formas de governo e governos de fato, que nunca sendo a realização ou aplicação de um princípio, são constituídos pela luta entre os regimes e pela luta de classes que é o fator no qual as transações alcançam sínteses históricas concretas; 3) a luta e transações entre princípios, regimes e formas de governo não são resolvidas no terreno exclusivo da política; na realidade, essas formas de governo tendem sempre à dissolução em razão da sua localização dentro da economia.

Assim, o federalismo é delineado como projeto no momento em que ele reúne as propriedades de equilíbrio entre liberdade e autoridade, centralização e descentralização do poder. Mas sendo fundamental, a ideia de federalismo não esgota essa perspectiva, ela exige a compreensão do mutualismo. A obra de Proudhon e sua conexão com o movimento operário e socialista é absolutamente incompreensível se não levarmos em consideração o seu livro póstumo "A Capacidade Política das Classes Operárias" (1865). O livro é desencadeado pela discussão acerca do Manifesto dos 60 Operários do Senna ${ }^{4}$ na sociedade francesa e a reação crítica de Proudhon ao projeto de um conjunto de operários de apresentar candidatos dentro das eleições do regime imperial francês. Toda a primeira parte do livro é a elaboração da sua posição política

\footnotetext{
${ }^{4}$ Declaração política de ativistas operários defendendo uma política de classe, que os trabalhadores se apresentassem como classe para disputar as eleições.
} 
apresentada um ano antes (de boicote às eleições e de defesa da "associação" como principal projeto da classe trabalhadora).

Neste livro temos uma teoria da ação e da constituição da classe enquanto agente, enquanto força coletiva; ao contrário da visão hegeliana e marxista na qual a história move o agente (que não é senão o realizador da razão ou da produção), a teoria da capacidade política está centrada no reconhecimento das condições subjetivas da formação da classe (a autoconsciência) e nas condições objetivas (a sua autoatividade). A partir da análise do episódio das eleições ele coloca a questão (que a princípio surgia no plano jurídico e no reconhecimento da capacidade eleitoral e política do trabalhador) e eleva esse tema ao patamar propriamente sociológico. Vejamos:

A questão das candidaturas operárias, resolvida negativamente pelas eleições de 1863 e 1864 implica a da capacidade política dos trabalhadores mesmos ou, para servir-me de uma expressão mais geral, do povo. O povo, a quem a revolução de 1848 deu a faculdade de votar, é ou não capaz de julgar em política? É capaz de formar sobre as questões que interessam à coletividade social uma opinião em harmonia com sua condição, seu porvir e seus interesses? É capaz de pronunciar, em consequência, sobre as mesmas questões submetidas à sua arbitragem direta e indireta, um julgamento fundamentado? É capaz de constituir um centro de ação que seja fiel expressão de suas ideias, suas visões e suas esperanças, e que esteja encarregado de procurar a execução de seus projetos? (...) Tal é a inevitável questão suscitada pelas candidaturas operárias da classe trabalhadora, questão à qual é absolutamente indispensável responder: o povo é ou não capaz? Os Sessenta, preciso felicitar-lhes por isso, se declararam corajosamente pela resposta afirmativa. (PROUDHON, 2003)

O problema da capacidade política é a questão de fundo levantada pelo debate sobre o manifesto dos 60 operários do Senna. O manifesto dos 60 operários foi respondido por outro, o contramanifesto dos 80 - que recusou os argumentos da luta de classes e foi tomado por Proudhon como a reprodução das ideias da burguesia que estavam se difundindo na grande imprensa: "Descarto que esses operários, como cidadãos e como trabalhadores, valessem tanto como os outros; certamente não tinham nem sua originalidade nem sua ousadia (Proudhon, op.cit).

A partir disso ele parte para diferenciar a noção de capacidade política real e legal. É interessante observar que nessa diferenciação ele toma o caso concreto do sufrágio universal e seu significado na evolução política francesa: o voto censitário tinha como prerrogativa a suposição da capacidade política dos "proprietários", ou seja, os proprietários seriam inerentemente capazes politicamente. Depois ele questiona a utilização de critérios de sexo, idade, raça para atribuir o mesmo reconhecimento (Proudhon, 2003). 
Desnaturalizando a capacidade política, separada da capacidade legal instituída pela sociedade dominante, ele irá afirmar a capacidade real a partir de um conjunto de condições que dizem respeito à relação do sujeito individual e coletivo com a multiplicidade objetiva do mundo sobre a qual incide através da sua atividade.

\begin{abstract}
Assim queiramos ou não, desde o momento em que nos propomos a tratar como historiadores e como filósofos a capacidade política, devemos sair do terreno das ficções e chegarmos à capacidade real, única de que falaremos adiante. Para que em um sujeito, indivíduo, corporação ou coletividade haja capacidade política se requer três condições fundamentais: $1^{\circ}$. Que o sujeito tenha consciência de si próprio, de sua dignidade, de seu valor, da posição que ocupa na sociedade, do papel que desempenha, das funções que tem direito a aspirar, dos interesses que representa ou personifica; $2^{\circ}$. Que, como resultado dessa consciência plena de si próprio, afirme sua ideia, a saber, que conheça a lei de seu ser, saiba expressa-la pela palavra e explicá-la pela razão, não somente em seu princípio senão também em todas as suas consequências; $3^{\circ}$. Que desta ideia -assentada como profissão de fé- possa, segundo exijam as circunstâncias, extrair sempre conclusões práticas. (PROUDHON, 2003)
\end{abstract}

A capacidade política real engloba a legal e é definida por três dimensões cumulativas: $1^{\mathrm{a}}$ ) a autoconsciência (sentir-se), que expressa uma percepção valorativa e sensitiva do sujeito em relação a si; $2^{\mathrm{a}}$ ) a racionalização (ideológica, teórica), que implica que, além do autoreconhecimento, haja uma visão do mundo e dos seus interesses "para si” (pensar-se); $3^{\mathrm{a}}$ ) a práxis, a atividade transformadora de autorealização (fazer-se). Isso vai levar à teorização da capacidade política da classe operária como sujeito independente da burguesia, marcando uma diferença substantiva em relação ao marxismo ${ }^{5}$. A classe trabalhadora surge "por si”" (e isto é válido para os sujeitos políticos em geral) porque é preciso a capacidade política, e essa capacidade implica a constituição da classe por si e do sujeito por si.

Aqui o problema da participação nas eleições burguesas - e sua recusa - é o terreno para a defesa da construção de "centros de ação da classe operária", que seriam o principal fundamento do sindicalismo e a base para a sistematização da AIT. Nesse sentido, ao analisar a experiência da classe trabalhadora francesa Proudhon observa que esta se encontrava no processo de constituição dos seus centros de ação e de separação da política burguesa.

\footnotetext{
${ }^{5}$ Podemos dizer que Marx, diferentemente de Hegel, opera com duas categorias fundamentais, o real "em si" e o sujeito "para si". Na teoria das classes sociais a passagem da classe em si a uma classe "para si" é altamente problemática, porque sempre exige uma intervenção exterior que produza a consciência. Essa intervenção se dá pela ação do Partido, encarnação e germe da classe, que conduz a classe em si ao caminho da classe para si. Em Proudhon, essa exterioridade não existe, a classe se constitui pela autoconsciência, ela se faz "por si".
} 
Possuir a capacidade política é ter consciência de sí mesmo como indivíduo de uma coletividade, afirmar a ideia que dela resulta e procurar sua realização. O problema da capacidade política na classe trabalhadora - do mesmo modo que na burguesia e em outras épocas na nobreza - se reduz, portanto, ao seguinte: a) Se a classe trabalhadora, sob o ponto de vista de suas relações com a sociedade e o Estado, adquiriu consciência de si própria; se como ser coletivo, moral e livre, se distingue da classe burguesa; se separa de seus interesses os seus, se aspira a não confundir-se com ela; b) Se possui uma ideia, a saber, que formou a sua própria constituição; se conhece as leis, condições e fórmulas de sua existência; se prevê seu destino, seu fim; se compreende a si própria em suas relações com o Estado, a Nação e a ordem humana; c) Se desta ideia é capaz de deduzir, para a organização da sociedade, conclusões práticas que lhe sejam próprias, e se, no caso em que o poder venha a cair em suas mãos porque caiu ou se tenha abdicado a burguesia, poderia criar e desenvolver uma nova ordem política. Nisto consiste a capacidade política, não em outra coisa. (PROUDHON, 2003)

$\mathrm{O}$ trecho acima deixa claro os elementos da sociologia aplicada à organização: a ideia é que o proletariado tinha depois de 1848 conseguido sua autoconsciência e sua racionalização, mas ainda não tinha constituído seus centros de ação, uma prática geral adequada a uma nova ordem política. Continuava assim ainda atrelado à política burguesa e não conseguia, por isso, constituir-se como sujeito por si. Dessa maneira, o problema do proletariado era conseguir separar-se da política da burguesia para constituir uma nova ordem.

Desse debate sobre capacidade política podemos perceber que surge certo posicionamento: os operários estavam tentando se separar da oposição burguesa e buscavam intervir na vida política a partir de candidaturas próprias. Proudhon irá alargar o problema e colocar que, na realidade, restringir a luta pela capacidade política à luta pelo Estado - dentro da oposição burguesa ou fora dela com candidaturas próprias - era restringir o problema. Ou seja, ao alargar o problema ele cria o espaço teórico para a ideia de uma ação coletiva de classe que não se resumisse à política como atividade de Estado, afirmando assim o espaço das sociedades ou associações operárias. A diferenciação de classes se colocava como imperativa: ela era o fundamento do processo de tomada de consciência e não um elemento artificialmente criado por facciosos, como a imprensa imperial queria fazer acreditar. Mas ao mesmo tempo, essa consciência de classe não era apenas uma expressão mecânica do mundo objetivo. Aqui ele segue demonstrando que a capacidade política necessita da formulação de uma ideia, de uma teoria e uma ciência. Ou seja, outro componente que Proudhon irá acrescentar é a necessidade, como parte da tomada de autoconsciência do proletariado, de constituir uma ciência. Mas o sentir-se é precondição do pensar-se e a experiência associativa é central para isso. No terceiro capítulo do livro, Proudhon elabora um conceito que então 
passaria a ser central: o conceito de "associação". A "associação" é assim um princípio que engloba o sentir-se e o pensar-se, e logo, a associação coletiva é o fator decisivo da construção da autoconsciência.

A manifestação da consciência sucede, nos grupos humanos, a revelação da ideia. Esta sucessão está indicada pela natureza e explicada pela psicologia. A inteligência no ser pensante tem por base a condição primeira o sentimento. Para conhecer-se, ao homem é indispensável que sinta. Daí o zelo com que o poder persegue e restringe as reuniões populares, as assembleias, as associações, tudo o que pode despertar nas classes proletárias a consciência de si próprias. Querem impedir que reflitam e conciliem e para isso empregam o meio mais eficaz que é impedir que sintam. (PROUDHON, 2003)

Logo, o sentir-se e o pensar-se se encontram num fazer-se específico, a associação. O conceito de "associação" assim sintetiza esse processo de autoconsciência, racionalização e práxis que expressa a capacidade política. O conceito de associação aparece então profundamente ligado, de um lado, à objetividade da divisão de classes, e, de outro, ao processo de transformação da "classe em si" numa classe "por si"; é a associação, o meio e o fim já que ela expressa essa tomada de consciência e ela garante a capacidade política.

É com base nesse conceito que ele irá apresentar dois outros conceitos que vão marcar sua diferença em relação ao marxismo e às demais correntes liberais e estatistas. O conceito de reciprocidade/mutualidade e o conceito de força coletiva, que surgindo no início de sua obra com um sentido econômico (em si) irá adquirir também um sentido sociopolítico (por si). Este conceito de reciprocidade e mutualidade surge como parte da crítica ao conceito de comunidade, base da sua crítica ao "comunismo" ou sistema de Luxemburgo. Proudhon chama o sistema de Luxemburgo ou comunismo ${ }^{6}$ a teoria de Louis Blanc, de um intervencionismo estatal que visa estabelecer a estatização das propriedades em nome da "coletividade". A oposição então existente na classe trabalhadora seria entre os partidários da comunidade e autoridade e os partidários da liberdade e reciprocidade. Essas duas ideias antagônicas corresponderiam a dois sistemas diferentes (para poder compreender plenamente as definições abaixo, é preciso remeter ao livro "Do Princípio Federativo", em que a teoria da federação completa a teoria da associação mutualista exposta no livro "Da Capacidade Política das Classes Operárias”). O mutualismo assim é a extensão para a teoria econômica de um princípio

\footnotetext{
"É importante observar que o termo "comunismo", apesar de estar hoje inevitavelmente associado ao marxismo, designava diferentes sistemas teóricos e políticos como o de Cabet e mesmo de alguns Saintsimonianos.
} 
de "justiça" ou igualitarista, o da troca igual que corresponde na teoria federativa ao "pacto" federal. A ideia de mutualidade é em certo sentido o correspondente econômico da ideia de federação. Por outro lado, comunidade para Proudhon é a "ideia econômica" de Estado elevada até a negação do indivíduo e das coletividades reais.

Estamos falando então de uma teoria do poder que começa com a análise do dualismo político e da sucessão dos regimes e formas de governo, supondo a teoria e leis do desenvolvimento contraditório do capitalismo, que culmina com a afirmação de que a classe trabalhadora traz em si dois novos princípios, o princípio federativo (e logo, um embrião de uma nova forma de governo) e o princípio mutualista, (antagônico ao princípio de acumulação, embrião de uma economia socialista). Logo, a capacidade política da classe trabalhadora e sua constituição como força sociopolítica seria um dos elementos a explicar a possibilidade do surgimento de um novo regime político e uma nova economia.

\section{Mutualismo, coletivismo e ação direta: transformações históricas dos símbolos do anarquismo}

Várias pesquisas têm revisitado a história do movimento operário e socialista e trazido nova documentação sobre o anarquismo, o proudhonismo, o coletivismo e sua evolução histórica. Obras como L'Internationale: documents et souvenirs/A Internacional: documentos e recordações (Guillaume, 1907), Naissance de l'anarchisme/Nascimento do Anarquismo (Ansart, 1970), La Internacional Obrera (García; Fedeli, 1978), Workers Themselves/Os Trabalhadores por Si (Thorpe, 1989), Black Flame/Chama Negra (Van Der Walt, 2009) e The Origins of French Labour Movement/As origens do movimento trabalhista francês (Moss, 1980). Essas pesquisas permitem que façamos algumas afirmações e proposições.

Proudhon elabora sua teoria a partir do saber e do fazer operário. Associação e Mutualidade eram categorias do movimento social, da formação dos sindicatos e cooperativas. A constituição do proudhonismo no movimento operário francês seria a expressão ideológica do "obreirismo" (no sentido positivo, como doutrina da afirmação da classe trabalhadora como sujeito histórico e da afirmação do direito de associação dos trabalhadores como fator positivo da ordem política) que reconhecia: 1) a divisão da sociedade em classes e a necessidade de uma organização dos trabalhadores independente da oposição republicana e do setor monárquico; 2) que essa associação 
visava não somente à defesa de interesses e à resistência contra a exploração, mas especialmente transformar a estrutura de classes fundada na propriedade privada; 3) que a ação dos trabalhadores não poderia se restringir a candidaturas operárias, e que a práxis da sua política era mais ampla e deveria ser voltada para sua autoconsciência; 4) que a ordem política que deveria surgir seria "anárquica e mutualista", ou seja, o federalismo (a federação agrícola-industrial), como corolário da centralidade dos trabalhadores e da igualdade e liberdade. Esse obreirismo então fundia o anarquismo como forma de governo e economia com a defesa de certa prática associativa e política centrada na classe trabalhadora. $\mathrm{O}$ anarquismo surge então como parte dessa perspectiva trabalhista, de afirmação teórica, ontológica e política da centralidade do trabalho e dos explorados na economia e sociedade.

É por isso que ele vai se fundir tanto com a prática de resistência, gerando assim o associativismo e o "sindicalismo" da idade heroica quanto o anarquismo que Bakunin irá desenvolver, ao acrescentar as formas práticas e organizativas que o próprio Proudhon tinha colocado como condição necessária da capacidade política. Uma das grandes dificuldades da historiografia é que esse processo foi expresso por símbolos variados, em termos nacionais e também contextuais. Por isso, alguns autores ao associarem Proudhon ao mutualismo, consideram que Proudhon era reformista em razão da pratica mutualista ser "reformista". Esse equívoco deriva da pouca densidade das fontes e o pouco rigor metodológico. O mutualismo, baseado nas ideias de Proudhon, teve pelo menos duas grandes expressões: um mutualismo moderado e parlamentar (expresso pelo manifesto dos 60 operários do Sena) e um mutualismo de esquerda ou radical, desenvolvido por dirigentes de associações mutualistas como Varlin, que seria um dos principais animadores da AIT. Esses mutualistas radicais, franceses, belgas e suíços seriam os elaboradores da concepção coletivista, que enfatizava o papel da associação coletiva na emancipação operaria e na revolução social. Logo, o coletivismo se tornou a concepção dominante dentro das associações e, longe de ser uma ruptura com o mutualismo, ele foi sua radicalização revolucionaria (Moss, 1976). Bakunin irá se definir como proudhonista, e o bakuninismo é assim um tipo de interpretação revolucionária da obra de Proudhon (realizada por ele e pelos teóricos da Federação do Jura). Logo, as categorias mutualismo, coletivismo devem ser compreendidas dentro do seu contexto de enunciação e não como categorias transcendentes e em si.

Nesse sentido, podemos falar que o proudhonismo sintetiza sua contribuição prática pela introdução de alguns conceitos e práticas no movimento social: a prática da 
associação como meio de emancipação por si; a ideia de federação e mutualidade, como prática de divisão do poder e igualdade econômica. Essas duas práticas irão corresponder assim ao que podemos chamar de primeira geração de proudhonistas que irão se diferenciar entre "moderados" como Toulain e radicais ou insurrecionalistas, como Varlin. Mas vejamos, assim como Toulain, Varlin foi dirigente de sociedades mutualistas e da própria Associação Internacional dos Trabalhadores. Logo, o mutualismo nessa primeira geração se diferencia internamente entre alas radicais. A segunda geração de proudhonistas é composta pela entrada de Bakunin, dos exilados russos e de militantes belgas e suíços que iriam integrar a "Federação do Jura", que reuniu militantes como James Guillaume. Nesse contexto, a oposição entre mutualistas e coletivistas se desloca, ganhando outras oposições como anarquistas x comunistas e bakuninistas x marxistas. Não é por coincidência que a Comuna de Paris tenha retomado o projeto federativo de comunas, a própria AIT a ideia da libertação por si (o filosofema “A emancipação dos trabalhadores é obra dos próprios trabalhadores" é expressão disso) e que as organizações de trabalhadores no final do século tenha assumido o nome de federações e confederações ${ }^{7}$. Mutualismo, coletivismo foram símbolos empregados para demarcar a vinculação de uma pratica de resistência social com uma teoria política; o proudhonismo foi assim sucessivamente mutualista, coletivista e bakuninista. Mas o elemento fundamental de todas essas categorias e símbolos foi que elas vincularam o projeto da libertação da classe por si com uma pratica de resistência concreta.

A terceira geração a retomar as práticas proudhonistas seria a do final do século XIX, dos sindicalistas revolucionários. Outro símbolo que seria fundamental foi o conceito de ação direta (Pouget e Lamberet, 1910), elaborado no início do século XX pelo sindicalismo revolucionário (especialmente por Emile Pouget, ativista da CGT francesa): ação direta é um conceito complexo, mas ele sintetiza perfeitamente a teoria da classe por si: é a ação dos próprios trabalhadores - ação de resistência e ação associativa - que pode libertar a classe trabalhadora coletivamente, não é nenhuma ação de cima e de fora.

\footnotetext{
${ }^{7}$ Para citar as mais importantes, Confederação Geral dos Trabalhadores (França), Federação Obreira Regional Argentina (Fora) Confederação Nacional do Trabalho (Espanha), Confederação Operária Brasileira, dentre muitas outras. Logo, grande parte do associativismo sindical foi fundado sobre a teoria e prática federalista.
} 
O anarquismo como fenômeno histórico está ligado então ao surgimento e transformações do proudhonismo. Por outro lado, a teoria da classe por si, elaborada por Proudhon, mutualistas e coletivistas, sintetizada no conceito de ação direta, tornou-se símbolo de uma concepção teórica e política de resistência anticapitalista. Essa é a importância fundamental do pensamento de Proudhon - marginalizado, subalternizado e negado pelos paradigmas dominantes - e de sua sociologia insurgente.

\section{Referências Bibliográficas:}

ANSART, Pierre. Naissance de l'anarchisme. Paris: Presses universitaires de France, 1970.

CORREAA, Felipe. Problemáticas teóricas e históricas dos estudos de referência do anarquismo. Revista Brasileira de Informação Bibliográfica em Ciências Sociais. São Paulo, n. 76, 2. ${ }^{\circ}$ semestre de 2013. (Publicada em julho de 2015)

DURKHEIM, Emile. El socialismo. Madri: Editora Nacional, 1982.

FERREIRA, Andrey Cordeiro. Anarquismo, pensamento e práticas insurgentes. In: De baixo para cima e da periferia para o centro: textos políticos, filosóficos e de teoria sociológica de Mikhail Bakunin. Niterói: Alternativa, v. I, 2014, p.21-61.

GARCÍA, Victor; FEDELI, Ugo. La internacional obrera. Barcelona: Júcar, 1978.

GUILLAUME, James. L'Internationale: documents et souvenirs (1864-1878). Société nouvelle de librarie et Édition, v.2, 1907.

GURVITCH, Georges ; PROUDHON, Pierre-Joseph. Proudhon: sa vie, son Óuvre, avec un expos de sa philosophie. Paris: Presses universitaires de France. 1965.

JOLL, James. Anarquistas e anarquismo. Lisboa: Dom Quixote, 1977.

MARX, Karl. Sobre Proudhon (carta a J. B. Von Schweitzer). In: Marx e Engels Obras Escolhidas em três tomos. Lisboa-Moscou: Avante!-Progresso, v. II, 1982.

MARX, Karl; ENGELS, Friedrich. Miséria da Filosofia. São Paulo: Global, 1985. 
MOSS, Bernard H. The Origins of the French Labor Movement: The Socialism of Skilled Workers, 1830-1914. Berkeley: University of California Press, 1976.

POUGET, Émile; LAMBERET, Renée. L'Action directe. Paris: Editions de la Guerre sociale, 1910.

THORPE, Wayne-Westergard. The Workers Themselves. Syndicalism and International Labour: the Origins of the International Working Men's Association, 1913-1923. Dordrecht: Kluwer Academic Publisher, v.12, 1989.

TRAGTENBERG, Maurício. Kropotkin: textos escolhidos. Porto Alegre: L\&PM, 1987.

VAN DER WALT, Lucien; SCHMIDT, Michael. Black Flame: the revolutionary class politics of anarchism and syndicalism. Oakland: AK Press, 2009.

WOODCOCK, George. História das ideias e movimentos anarquistas: o movimento. Porto Alegre: L\&PM, 2002. 